\title{
Flax Seed and Climacteric Symptoms - A Review
}

\author{
Sri Devi Rajavi ${ }^{1}, K$ amala Kuppu Samy ${ }^{2}$ \\ ${ }^{1}$ Department of OBG Nursing, Vinayaka Mission's Research Foundation (Deemed to Be University) Salem, Tamilnadu, \\ India. 2 Department of Paediatric Nursing, Vinayaka Mission's College of Nursing, Karaikal, Puducherry, India.
}

\section{ABSTRACT}

\section{BACKGROUND}

Universally every woman faces menopause and feeling of onset of uncomfortable physical, psychological and emotional changes. Many fear about their loss of beauty and sexual life. The word menopause has come from Greek word "Menos" meaning menstruation and "Pause" meaning stopping of the menstrual period. ${ }^{1}$ The loss of ovarian follicular activity or the dwindling function of ovaries at the end of reproductive life which leads to permanent cessation of menstruation is known as menopause or climacteric. The period of time when women passes from reproductive to non-reproductive stage is menopause transition. The life after menopause is the stage of postmenopausal period. In majority of women, menopause occurs without any physical or psychological symptoms. But in some of the women there will be marked physical and psychological symptoms. Symptoms of the climacteric are multiple and vague. These climacteric symptoms are due to decrease in oestrogen level and increase in Gonadotrophin level in the body, but the exact mechanism is unknown. The climacteric symptoms are grouped into vasomotor symptoms (hot flushes, night sweats), cardiovascular symptoms and cerebro-vascular effects (hypertension, palpitation, heart disease), neurological \& psychological symptoms (anxiety, depression, insomnia, irritability, malaise, loss of libido / lethargy), general symptoms (fatigue, headache, general weakness, vertigo, breast tenderness, skin pigmentation, dyspareunia, indigestion or constipation, obesity), physical symptoms / changes (atrophy of secondary sexual characters, atrophy of internal genital organs, osteoporosis, skin becomes thick and coarse, straggling growth of hair). ${ }^{2}$

\section{KEY WORDS}

Flax Seed, Climacteric Symptoms, Menopause
Corresponding Author: Prof (Mrs). Sridevi Rajavi Professor \& Head, Vinayaka Missions College of Nursing Karaikal, Puducherry, India.

E-mail: nila.sridevi@yahoo.com/ srideviveeravel@gmail.com.

DOI: $10.14260 /$ jemds/2021/267

How to Cite This Article:

Rajavi SD, Samy KK. Flax seed and climacteric symptoms - a review. J Evolution Med Dent Sci 2021;10(17): 1257-1264, DOI:

10.14260/jemds/2021/267

Submission 06-03-2020,

Peer Review 30-01-2021,

Acceptance 06-02-2021,

Published 26-04-2021.

Copyright (C) 2021 Sri Devi Rajavi et al. This is an open access article distributed under Creative Commons Attribution License [Attribution 4.0 International (CC BY 4.0)] 


\section{CLIMACTERIC SYMPTOMS} OF WOMEN IN INDIA

In India, climacteric symptoms differ among women. The mean age of menopause according to the Indian Menopause Society's (IMS) in India is $\mathbf{4 7 . 5}$ years. The life expectancy is 71 years. The Population Projections survey in India reveals that the number of menopausal women is about 43 million. It is expected to reach 103 million in $2026 .^{3}$

In India, environmental and genetic factors are the main reason for premature menopause. During this period, majority of Indian women living in rural areas have the complaint of urogenital symptoms and general body aches and pains whereas women in urban areas complain about having mood swings, hot flashes, psychological challenges and challenges in intercourse which was proved by many research studies. In human life span development, menopause phase signifies the normal aging process, it is not a disease. 4

\begin{tabular}{|cc|}
\hline Types of Menopause & Age in Years \\
Natural menopause & $45-55$ years \\
Premature menopause & Less than 40 years \\
Early menopause & $40-45$ years \\
Delayed menopause & More than 55 years \\
\hline Induced menopause (surgical, radiation, chemotherapy) & At any age. \\
\hline \multicolumn{2}{|c|}{ Relation of Menopause with Age } \\
\hline
\end{tabular}

\section{Factors That Affect the Age of Menopause}

- Low body weight.

- $\quad$ Family history of early menopause.

- Living in high altitudes.

- Current and prior cigarette smoking.

- Vegetarianism.

- Malnourishment in women. ${ }^{5}$

\section{Factors Leading to Early Menopause}

- Shorter menstrual cycle.

- Nulliparous women.

- Smoking habits.

- Genetic factors e.g., ER - alpha Polymorphism.

- Body mass index (BMI) less than 25.

- Ovary - Oophorectomy, chemotherapy, ovarian radiation.

- Hysterectomy, uterine artery embolization. ${ }^{5}$

\section{Factors Contributing to Late Menopause}

- Oral Contraceptive pills.

- Multiparity.

- Longer menstrual cycle.

- Genetic factors.

- $\quad$ Late age of menarche. 5

\section{PHYTOESTROGENS IN CLIMACTERIC SYMPTOMS}

Recent research studies have proved that the hormonal replacement therapy for alleviating menopausal symptoms had side effects as cancer in some patients. In both men and women, climacteric symptoms caused due to low oestrogen levels can be alleviated by phytoestrogens (non-hormonal treatment). Phytoestrogens are plant-based oestrogens. Their structural similarity is as same as oestrogen. These plantbased oestrogens (i.e., phytoestrogens) when consumed in recommended quantity will decrease the menopausal symptoms by binding to oestrogen receptors and stimulate the activities of oestrogen. $3,2,6$

\section{MECHANISM OF ACTION OF PHYTO- ESTROGENS AS OESTROGEN REPLACEMENT}

Phytoestrogens act by attaching to oestrogen receptors (ER) present in our body. The two variants of the oestrogen receptors are alpha (ER -) and beta (ER -). The main structural elements that help phytoestrogens to affix with high affinity to oestrogen receptors and exhibit estradiol-like effects are:

- The phenolic ring that is very essential for binding to oestrogen receptor.

- Molecular weight of phytoestrogens is 272 which is similar to oestrogen.

- At the oestrogen receptor site, the ring of isoflavones imitates the ring of oestrogens.

- Optimal hydroxylation pattern. It means the hydroxylation pattern is similar in isoflavones and estradiol which helps in easy binding.

\section{Benefits of Phytoestrogens}

- During perimenopause, there will be fluctuations in oestrogen hormone levels which leads to climacteric symptoms.

- Phytoestrogens help naturally to cope with climacteric symptoms that occurs due to hormone imbalances and it is beneficial for the women in menopause period.

- Phytoestrogen is very essential for menopausal women to rebalance their hormones during perimenopausal period.

\section{Other Potential Benefits of Phytoestrogens 1. Relief from Menstrual Issues \\ When oestrogen level drops in perimenopausal women, there may be some menstrual issues like heavy bleeding, short cycle, severe premenstrual symptoms, lower abdominal pain etc., which can affect mood and energy levels. Consumption of plant-based oestrogens during this period helps to balance her hormone levels and relieve symptoms.}

\section{Promotes Bone Strength}

The bones become weaker and brittle due to oestrogen deficiency during perimenopause period. When hormonal replacement therapy (HRT) is used to promote bone health it may cause uncomfortable side effects. Many research studies have proved that phytoestrogens may be a natural alternative to promote bone health. A study conducted in 2011 found 
that intake of phytoestrogens helped to combat postmenopausal osteoporosis.

\section{Reduces the Symptom of Hot Flushes}

Hot flush is one of the major climacteric symptom during menopausal period due to oestrogen deficiency. Hot flashes followed by sweating and women becomes uncomfortable. Phytoestrogens help to relieve uncomfortable hot flashes and night sweats too. A study conducted in 2014, proved that phytoestrogens reduced the frequency of hot flashes in menopausal women without any serious side effects.

\section{Treatment of Acne}

The main cause of acne in women is due to the increased level of androgen hormones (male hormone). Intake of plant-based oestrogens such as flaxseed helps to combat acne by rebalancing hormone levels.

\section{Fighting Breast Cancer}

The risk of breast cancer increases after menopause due to oestrogen deficiency. Some menopausal women who are taking hormone replacement therapy for combating climacteric symptoms are more prone to breast cancer. Phytoestrogens are beneficial in fighting against breast cancer. A research study conducted in 2009 proved that consuming soy foods (plant-based oestrogens) decreased the number of death and recurrence of breast cancer among women with breast cancer. A study conducted in 2015 proved that intake of foods rich in phytoestrogens inhibited the growth of breast cancer cells.

\section{Promoting Heart Health}

Omega 3 fatty acids is rich in foods containing phytoestrogens. Omega 3 fatty acids are very essential for heart health for both men and women. A study conducted on 2016 proved that intake of foods rich in phytoestrogens helped to treat a condition that affects the arteries and improved heart health in postmenopausal women.

\section{Food Groups Rich in Phytoestrogens}

\section{Seeds and Nuts}

Flaxseeds, Sunflower seeds, sesame seeds, walnuts, almonds, etc., are some of the seeds and nuts which are rich in phytoestrogens.

\section{Soy Food Products}

Soy food products such as tofu, soya beans, tempeh, miso paste, miso soup is rich in phytoestrogens.

\section{Herbs}

Certain herbs such as hop, licorice root, red clover, etc., are rich in phytoestrogens.

\section{Grains}

Some grains such as oats, barley, wheat germ contains phytoestrogens.

\section{Fruits}

Apples, grapes, cranberries, carrots, pomegranates, strawberries are some of the fruits rich in phytoestrogens.

\section{Vegetables}

Vegetables such as lentils, yam, sprouts, alfalfa sprouts, mung beans, etc., are a good source of phytoestrogens.

\section{Liquids}

Some of the beverages that are rich in phytoestrogens such as coffee, bourbon, beer, red wine etc., oils like olive oil, jasmine oil are also the richest source of phytoestrogens.

\section{FOODS HIGH IN OESTROGEN}

Following foods are rich in oestrogen

1. Flaxseed - $(163,133)$

2. Soybeans - $(45,724)$

3. Soy nuts - $(21,306)$

4. Textured veggie protein - $(8,923)$

5. Soy milk - $(7,422)$

6. Soy yogurt - $(6,576)$

7. Flax bread - $(3,770)$

8. Sesame seed - $(2,722)$

9. Miso paste $-(2,463)$

10. Multigrain bread - $(2,207)$

11. Miso Soup - $(1,691)$

12. Soy protein powder - $(1,591)$

13. Doughnuts - $(1,568)$

14. Soy protein bar $-(1,525)$

15. Black bean sauce - $(1,119)$

16. Hummus - (605)

17. Veggie burger - (484)

18. Soy bacon bits - (482)

It is believed that consumption of plant-based diet and food that contains phytoestrogen makes an individual person to be healthy. Highest level of phytoestrogens are found in soy products, flax seed which are proved by research findings that these two foods can significantly reduce menopausal symptoms. ${ }^{7,8}$

Colli. MC et al. (2012), conducted a study to evaluate the efficacy of flaxseed meal and flaxseed extract in reducing climacteric symptoms of menopausal women. 90 postmenopausal women were selected as sample and randomly distributed in three groups. The first group was given 1 gram of flaxseed extract (50 mg lignan) i.e. two 500 mg capsules daily. The second group was given 90 grams of flaxseed per day. The third group was given $500 \mathrm{mg}$ capsules which contains 1 gram of collagen (placebo) daily for 6 months. Pre-test and post-test for assessing menopausal symptoms were carried out using Kuppermann index for all the three groups. The results proved that the group I (flaxseed extract $\mathrm{P}=0.007$ ) and group II (flaxseed $\mathrm{P}=0.005$ )) were effective than placebo group in reducing climacteric symptoms. ${ }^{9,10,11}$

A recent study was conducted by researchers from Turkey's Izmir Katip Celebi University regarding quality of life among menopausal women. Sample size is 140 menopause women. The women were divided into four groups of 35. Group I \& II were given five grams of flaxseed per day. Group III received hormone replacement therapy consists of 2 milligrams of estradiol hemihydrate and 1 milligram of norethindrone acetate per day. Group IV was 
control group. Duration of study is 3 months. The study result was proved that the groups that consumed the 5 grams of flaxseed per day had less-intense menopausal symptoms. ${ }^{12,13}$

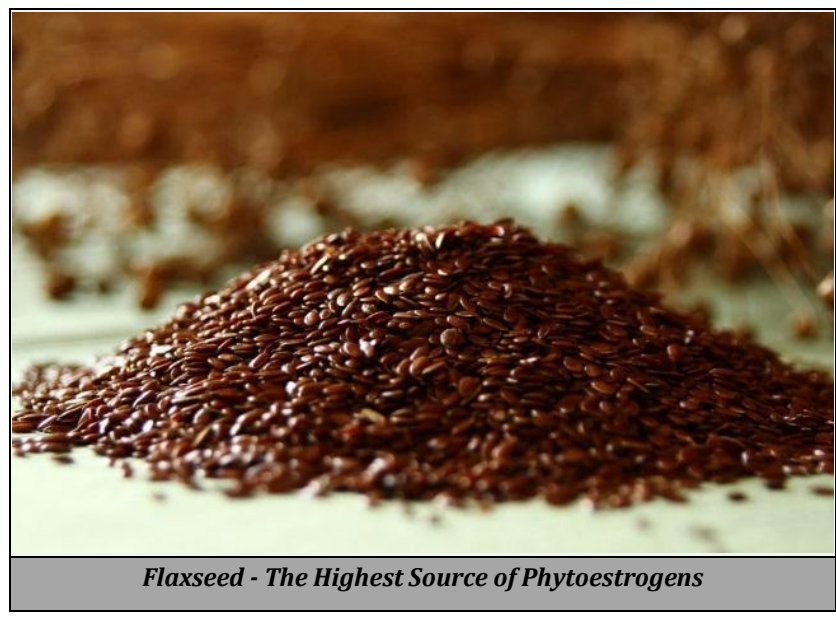

Flax seed or Linseed (Linum Usitatissimmum) belongs to the family Lineaceae, which is a blue flowering herb cultivated in temperate and tropical regions. The herb produces small seeds which are flat in shape and varies from golden yellow to reddish brown colour. The tip of the seed is pointed and has a seed coat, also named as testa. It also has an endosperm which is thin in nature, embryo and embryo axis. Flax seed nature is nutty taste and crispy texture. It is very unique among all oilseeds due to its high content of nutritional composition such as linolenic acid (ALA) and lignans. The countries where linseeds are grown abundantly are India, Ethiopia, China and United States. The largest producer of flax seed among world countries is Canada which is nearly $80 \%$. Either directly or after processing, every part of flaxseed is utilized for commercial purpose.7,14,15

\section{NUTRITIONAL COMPOSITION OF FLAXSEED}

Flaxseed has mainly three bioactive components. 1. alphalinolenic acid, 2. lignans (secoisoiariciresinol diglycosideSDG) and 3. dietary fiber. But its composition varies according to genetic factor, environment or climactic condition, method of drying, threshing, pre-cleaning, cleaning, size grading, treating, quality testing, packaging and labelling of seeds. Due to the presence of these three bioactive components in flaxseed or linseed, it is considered as functional or purposeful food.14,16

\section{a. Alpha-Linolenic Acid}

Alpha-linolenic acid (ALA) is the main functional component of flaxseed. Among vegetarian diet, flaxseed is an exclusive and richest source of omega- 3 fatty acid in the vegetarian diets. Omega- 3 fatty acids cannot be synthesized by our body since our body lacks certain enzymes which is necessary for the synthesis for these essential fatty acids. Hence, essential fatty acids need to be supplied or added in our daily diet.7 There are two groups of omega fats. One is omega- 3 fatty acids and the other is omega- 6 fatty acids. The types of omega- 3 fatty acids which are nutritionally essential area. 1 . Linolenic acid, 2. Eicosapentaenoic acid (EPA) and 3. docosahexaenoic acid (DHA). Many research studies have proved that all these three fatty acids reduce the risk of cardiovascular disease. ${ }^{17}$ Intake of flaxseed helps to lower blood pressure, cholesterol level and triglyceride levels.3,18,19

\section{b. Lignans}

The richest source of plant Lignans is flaxseed. ${ }^{20}$ Lignans are one of the bioactive components of flaxseed which are plant-based oestrogen. It is also rich in fiber. Lignans are present in cereals such as oats, wheat, barley, vegetables such as asparagus, broccoli, garlic, carrots, legumes such as beans, lentil, soybean, berries, fruits, tea and alcoholic beverages. ${ }^{1}$ The major lignin of flaxseed is secoisolariciresinol diglycoside. The biological level of estradiol decides the behaviour of the lignans. The lignans act as oestrogen antagonists at normal estradiol levels but in low oestrogen levels such as in postmenopausal women it acts as weak estrogen. ${ }^{21,20}$

\section{c. Dietary Fiber (Mucilage or Gum)}

Flaxseed is rich in fiber content. 15 gms of dry whole flaxseed provides around $20-25 \%$ of daily fiber requirement than ground flaxseed. In flaxseed there are both soluble and insoluble dietary fibers that are present. The proportion of soluble dietary fiber is 20:80 and insoluble dietary fibers is 40:60. The major insoluble fiber fraction consists of cellulose and lignin. The soluble fiber fraction consists of mucilage gums. ${ }^{22}$ Functional fiber consists of non-digestible carbohydrates such as resistant starch, oligosaccharides and non-starch polysaccharides. It is extracted from plants, purified and finally added to foods and other products. ${ }^{11}$ The sum of dietary fiber and functional fiber is the total fiber. In flaxseed, presence of rich dietary fibres helps in body weight reduction through hunger suppression. ${ }^{23,6}$

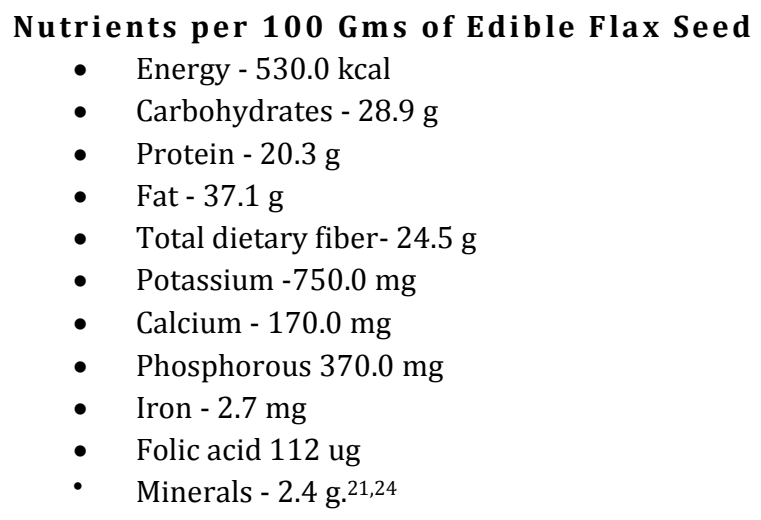

Flaxseed consists of diphenolic compounds (a molecule consists of phenyl group bonded to a hydroxyl group). Its structure is similar to the oestrogens present in our body. The amount of lignans found in flaxseed is nearly 100 to 800 times more than that found in other food groups. Many research studies have proved that the intake of flaxseed will be very effective in the treatment of climacteric symptoms such as hot flashes, night sweats, etc., The richest source of 
phytoestrogens present in flaxseed helps to balance the oestrogen deficiency and reduces climacteric symptoms. ${ }^{13,15}$

\section{Types of Flax Seed}

1. Ground Flaxseed

- Most beneficial type.

- $\quad$ Easy to digest and absorb nutrients. ${ }^{25}$

2. Whole Flaxseed

- Ideal for sprinkling on our food.

- $\quad$ Since very tiny may not be broken by chewing and can be undigested.

- So, no nutritional benefits. ${ }^{25}$

\section{Flaxseed Oil}

- It does not contain the fibre or lignans that ground or whole flaxseed contains.

- Lignans are removed during the process of extracting. ${ }^{25}$

\section{Storage of Flaxseed}

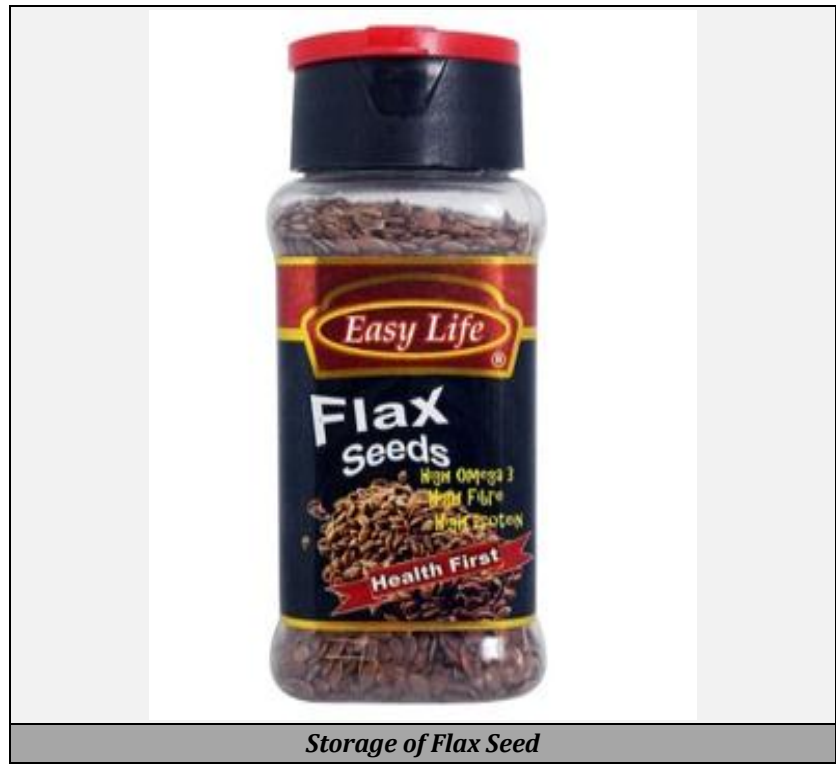

Ground or whole flaxseed can be stored in the fridge or the freezer in airtight containers because in warm environment the oil in flaxseed can go rancid quite quickly.

\section{DOSAGE OF FLAXSEED}

The two toxic compounds which are present in flaxseed such as Cyanogenic glycosides and Linatine, an anti-pyridoxine factor may influence adverse effect on the health and wellbeing of human population. But generally dry roasting of flaxseed for few minutes helps to eliminate the toxin cyanogenic glycosides. Recommended daily dose is 1 or 2 tablespoon per day or 40 grams daily for three to six months based on severity of symptoms.

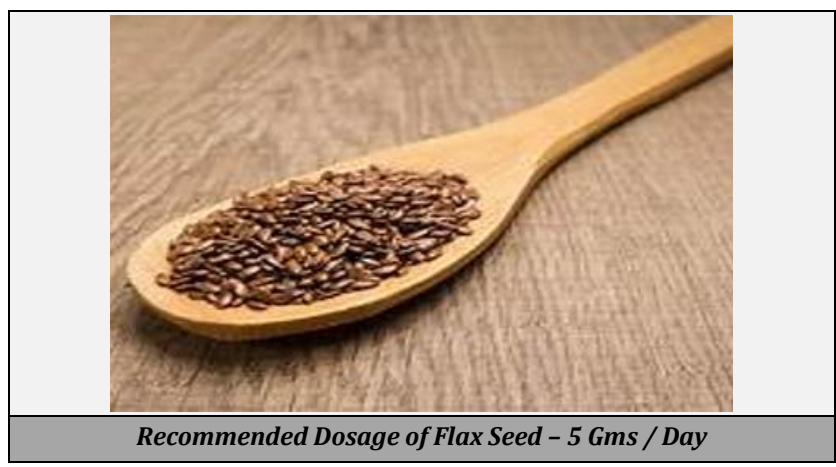

\section{Preparation of Edible Flaxseed}

- Take 100 gms of Flaxseed.

- Fry in a pan in slow heat for 5 minutes

- Cool it

- $\quad$ Store in a glass bottle

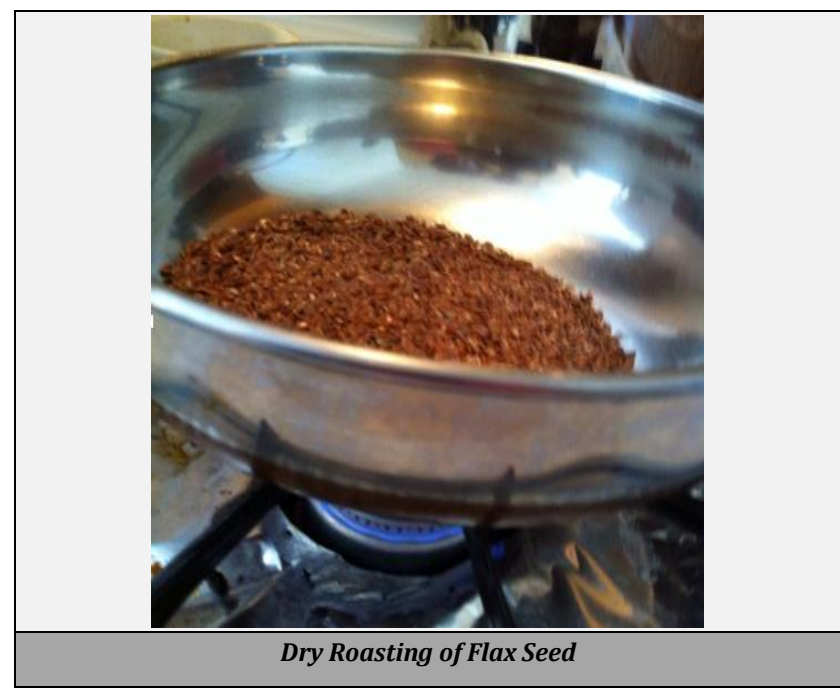

\section{RESEARCH STUDIES ON FLAX SEED}

Research studies proved that in 2015 Nuray Egelioglu Cetisli, $\mathrm{PhD}, \mathrm{RN}$, et al. conducted a study on Flaxseed beats HRT in reducing menopause symptoms. 140 postmenopausal women were selected as sample. The study was conducted by the researchers from the departments of Nursing and Pharmacy from Katip Celebi University. Four groups were taken for study. For Group one and group two, five grams of flaxseed per day was given in bulk quantity and encouraged them to consume for three months. Group three received hormone replacement therapy as 2 milligrams of estradiol hemihydrate and 1 milligram of norethindrone acetate per day. Group four is control group. Duration of study is three months. Menopause rating scale is used before and after intervention to assess the various menopausal issues including intensity and frequency. The study results proved that group one and group two had significant decrease in menopausal symptoms by an average of $10 \%$, whereas in control group menopausal symptoms increased by an average of $7 \%$. Thus, the study results proved that the consumption of flaxseed in recommended doses reduced the menopausal symptoms. Quality of life (QOL) scores also improved in group one and two whereas QOL scores 
decreased in group that consumed HRT and control group. ${ }^{12,25,26}$

Pruththi et al. (2012) has conducted a study on effectiveness of flaxseed on reducing hot flashes among women. 188 postmenopausal women with and without breast cancer were selected as sample for the study. For experimental group 7.5 grams (containing $410 \mathrm{mg}$ of lignan) of flaxseed was given for a period of 6 weeks and there was a placebo group. The results proved that the flaxseed group and placebo group similarly reduced hot flashes. ${ }^{27}$

Torkestani et al. (2012) conducted a study to assess intake of flaxseed and soya bean reduces hot flashes among postmenopausal women. The sample size is 90 . The sample was divided into group one, group two and group three. One group was given 25 gms of flaxseed, second group was given 25 gms of soya beans and third group was given 25 gms of wheat flour per day. Duration of the study is eight weeks. The study results proved that intake of flaxseed and soya bean decreased the severity and frequency of hot flushes. ${ }^{28}$

Andre Lemay., MD., Ph.D. et al. in 2002 conducted a research study to assess the serum lipid changes by a phytoestrogen dietary supplement compared with oral oestrogen-progesterone replacement in hypercholesterolemic menopausal women. Duration of study was 2 months. Here $40 \mathrm{mg}$ flaxseed ( $21 \mathrm{mg}$ lignan) versus $0.625 \mathrm{mg}$ conjugated oestrogen was given to the women with climacteric symptoms. The study result proved that both drugs were effective in the significant reduction of climacteric symptoms. ${ }^{28}$

Simbalista et al. in 2010 conducted a double-blind placebo-controlled randomized clinical trial to assess the effectiveness of intake of flaxseed on reducing menopausal symptoms. 38 postmenopausal women were selected as sample. They were given daily two pieces of bread which contains 25 grams flaxseed (46 mg lignin) for one group or wheat bran (less than $1 \mathrm{mg}$ lignin) for another group. Duration of study is 12 weeks. The study result proved that there was a significant decrease in frequency of hot flashes and vasomotor symptoms in both groups. But the intensity of hot flashes was reduced among the postmenopausal women who had consumed flaxseed in the form of two pieces of bread. ${ }^{29}$

\section{WAYS TO INCLUDE FLAXSEED IN OUR MEALS / DIET}

- Direct intake of roasted flaxseed.

- $\quad$ Sprinkle on sandwiches / toast.

- Include in baking cakes, bread, biscuits.

- $\quad$ Sprinkle on cereal / porridge.

- Adding in soups.

- Adding to salad dressings.

- $\quad$ Can be used to thicken fruit or veg smoothies. ${ }^{22}$

\section{Health Benefits of Flaxseed}

\section{Anti-Oxidant Functions}

Research studies have proved that antioxidant activity of flaxseed helps to decrease total cholesterol level as well as platelet aggregation. ${ }^{30}$ The antioxidant present in flaxseed are lignin Secoisolariciresinol Diglucoside (SDG), mammalian lignans enterodiol (ED) and enterolactone (EL). These antioxidants were more effective against DNA damage and lipid peroxidation. The essential fatty acids which are present in flaxseed such as omega -3- fatty acid has the potential protective role of allergic and respiratory disease. ${ }^{31}$

\section{Anti-Diabetic Functions}

Daily supplementation of Lignan for type 2 diabetic patients has proved by the research studies that there is good improvement in glycaemic control. Ingestion of flaxseed which is rich in dietary fibre helps to reduces peak blood glucose values. A research study has proved that administration of lignin capsules of $360 \mathrm{mg}$ per day for 12 weeks to diabetic patients with mild hypercholesterolemia resulted in reduced level of Creactive protein levels. ${ }^{15}$

\section{Reduces the Risk of Cancer}

Flaxseed intake reduces the risk of mammary and colonic cancer. Phytoestrogens and dietary fibres have cancer protective effects. The main cause of cancer in menopausal women is due to oestrogen deficiency. They face many climacteric symptoms. To overcome the climacteric symptoms some may be in the treatment of hormonal therapy which is at greater risk of developing breast cancer as a side effect of oestrogen therapy. A systematic review by Flower et al, 2013 considered that lignans and other flaxseed compounds helps in reducing menopausal symptoms for the women living with breast cancer. Many studies proved that intake of flaxseed decreased the risk of breast cancer. Also flaxseed demonstrated anti-proliferative effects in breast tissue of women who are at risk of developing breast cancer. Mortality risk also reduced among women living with cancer breast. ${ }^{15}$

4. $\quad$ Promoting Bone Strength and Preventing Osteoporosis Oestrogen hormone secreted in women promotes the strength of bones. During menopause, oestrogen level decreases sharply which can lead to bone loss. This is the reason of developing osteoporosis and increased risk of broken bones. So, when phytoestrogens are consumed by the menopausal women, it improves bone health and prevents the risk of broken bones. Many research studies proved that the intake of flaxseed helps to improve bone health and prevents osteoporosis. ${ }^{18,32}$

\section{Anti-Nutrients in Flaxseed}

Flaxseed also contains some anti-nutrients which may have adverse effect on the status of the health and wellbeing of human population. The main toxin in flaxseed is hydrogen cyanide. But the toxin will be removed in dry roasting for 5 minutes and it is safe when flaxseed is taken at the recommended daily doses. Daily recommended intake of flaxseed is 1 - 2 tablespoon per day. Many research studies have been proved that it can be consumed for 6 weeks to 6 months based on the severity of symptoms. ${ }^{33,34}$ 


\section{Side Effects of Flaxseed}

Recently flaxseeds have gained more attractiveness as a vegetarian food source of omega 3 fatty acids. The phytochemicals and lignans present in flaxseeds are beneficial for all especially for women. But on the other hand, consuming in large quantities may lead to some side effects.

\section{Loose Stools}

When flaxseeds are consumed in less quantity, it promotes regular, healthy bowel movements and prevents constipation. But when taken in excess or for some person with allergic condition, it leads to loose stools. Persons suffering from certain conditions such as irritable bowel syndrome should avoid consuming flaxseeds.

\section{Allergic Reactions}

The reported allergic reaction of flaxseed may be due to consumption of a greater number of flaxseeds. It can lead to anaphylaxis, obstructed breathing and low blood pressure levels. Other reactions include nausea, abdominal pain and vomiting.

\section{Intestinal Blockage}

Excess intake of flaxseed without consuming adequate fluids may lead to intestinal obstructions and blockage.

\section{Unsafe during Pregnancy}

Since flaxseed has the structural similarity of oestrogen and estrogenic effect, it may stimulate menstrual cycles. So, it is not recommended for pregnant women.

\section{For Women Trying to Conceive}

Newly married women and women trying to conceive, should avoid intake of flaxseed. And also, women with health conditions like polycystic ovary disease, uterine cancer, uterine fibroids, and ovarian cancer should be cautious about the use of flaxseed which may lead to infertility.

\section{Reactions with Other Medication}

Since flaxseeds are rich in both dietary fibre and functional fibre, it may sometimes prevent the absorption of certain medication and supplements. So, when a person is on oral medication, he must avoid consuming flaxseeds. Flaxseeds may also change the effects of blood thinning medication and blood sugar medicines. Persons who are consuming these medications should avoid intake of flaxseed.10,35

\section{CONCLUSIONS}

Many research studies proved that intake of flaxseed helps in reducing the climacteric symptoms in menopausal women. Hence, it is the responsibility of health care professionals to identify the menopausal women who suffer from severity of climacteric symptoms and create awareness about nutritional components and its effects in reducing climacteric symptoms of menopause.
Financial or other competing interests: None.

Disclosure forms provided by the authors are available with the full text of this article at jemds.com.

\section{REFERENCES}

[1] Meagher LP, Beecher GR, Flanagan VP, et al. Isolation and characterization of the lignans, isolariciresinol and pinoresinol, in flaxseed meal. J Agric Food Chem 1999;47(8):3173-80.

[2] Sourinejad H, Dehkordi ZR, Beigi M, et al. The use of flaxseed in gynaecology: a review article. Journal of Midwifery \& Reproductive Health 2019;7(2):1691-711.

[3] Borker SA, Venugopalan PP, Bhat SN. Study of menopausal symptoms and perception about menopause among women at 9 rural communities in Kerala. J Midlife Health 2013;4(3):182-7.

[4] Salhan S. Textbook of Gynaecology. $1^{\text {st }}$ edn. New Delhi: Jaypee Brothers Medical Publishers 2011:48-149.

[5] Bhodra B. Gynecology for Nurses. 1 $1^{\text {st }}$ edn. New Delhi: Jaypee Brother Medical Publishers 2014:270-8.

[6] Rondanelli M, Perdoni F, Peroni G, et al. Ideal food pyramid for patients with rheumatoid arthritis: a narrative review. Clin Nutr 2020;40(3):661-9.

[7] Daun JK, Barthet VJ, Chornick TL, et al. Structure, composition and variety development of flaxseed. In: Thompson LU, Cunnane SC, eds. Flaxseed in human Nutrition. $2^{\text {nd }}$ edn. Champaign, USA: AOCS Press 2003:140.

[8] Mnt - prod.medicalnews today.com.

[9] Case Adams, Naturopath. Copyrighter by Green Medinfo LLC-2015.

[10] Doctor.ndtv.com

[11] Hutchins AM, Slavin JL. Effect of flaxseed on sex hormone metabolism. In: Thompson LU, Cunnane SC, eds. Flaxseed in Human Nutrition. $2^{\text {nd }}$ edn. Champaign, Illinois: AOCS Press 2003:126-49.

[12] Cetisli NE, Saruhan A, Kivcak B. The effects of flaxseed on menopausal symptoms and quality of life. Holist Nurs Pract 2015;29(3):151-7.

[13] Jmrh.mums.ac.ir.

[14] Morris DH. Flax - a health and nutrition primer. $4^{\text {th }}$ edn. Flax Council of Canada 2007:9-19.

[15] Rubilor M, Gutierrez C, Verdugo M, et al. Flaxseed as a source of functional ingredients. J Soil Sci Plant Nutr 2010;10(3):373-7.

[16] Hussain S, Anjum FM, Butt MS, et al. Chemical compositions and functional properties of flaxseed flour. Sarhad J Agric 2008;24(4):649-54.

[17] Hurteau MC. Unique new food products contain good omega fats. Journal of Food Science Education 2004;3(4):52-3.

[18] Konar H. Dc Dutta's Textbook of Gynecology. $7^{\text {th }}$ edn. New Delhi: Jaypee Brothers Medical Publishers 2016:4651.

[19] Riediger ND, Othman R, Fitz E, et al. Low n-6: n-3 fatty acid ratio, with fish - or flaxseed oil, in high fat diet improves plasma lipids and beneficially alters tissue 
fatty acid composition in mice. Eur J Nutr 2009;47(3):153-60.

[20] Thompson LU, Chen JM, Li T, et al. Dietary flaxseed alters tumor biological markers in postmenopausal breast cancer. Clin Cancer Res 2005:11(10):3820-35.

[21] Catholictruthblog.org

[22] Oomah DB. Flaxseed as a functional food source. J Sci Food Agr 2001;81(9):889-94.

[23] Kristensen M, Jensen MG, Aarestrup J, et al. Flaxseed dietary fibers lower cholesterol and increase fecal fat excretion, but magnitude of effect depends on food type. Nutr Metab (Lond) 2012;9:8.

[24] Lemay A, Dodin S, Kadri N, et al. Flaxseed dietary supplement vrsus hormone replacement therapy in hypercholesterolemic menopausal women. Obstet Gynaecol 2002;100(3):495-504.

[25] http://www.bellaonline.com/articles/art18499.asp

[26] Pradhan AD, Manson JE, Rossouw JE, et al. Inflammatory biomarkers, hormone replacement therapy and incident coronary heart disease: prospective analysis from the Women's Health Initiative observational study. JAMA 2002;288(8):980-7.

[27] Pruthi S, Thompson SL, Novotny PJ, et al. Pilot evaluation of flaxseed for the management of hot flashes. J Soc Integr Oncol 2007:5(3):106-12.
[28] Torkestani NA, Attarha M, Heidari T, et al. The effect of fenugreek and flaxseed on menopausal hot flash. Complementary Medicine Journal 2011;1(1):68-74.

[29] Simbalista RL, Sauerbronn AV, Aldrighi JM, et al. Consumption of a flaxseed-rich food is not more effective than a placebo in alleviating the climacteric symptoms of postmenopausal women. J Nutr 2010;140(2):293-7.

[30] Allman MA, Pena MM, Pang D. Supplementation with flaxseed oil versus sunflowerseed oil in healthy young men consuming a low fat diet: effects on platelet composition and function. Eur J Clin Nutr 1995;49(3):169-78.

[31] Hu C, Yuan YV, Kitts DD. Antioxidant activities of the flaxseed lignin secoisolariciresinol diglucoside, its aglycone secoisolariciresinol and the mammalian lignans enterodiol and enterolactone in vitro. Food Chem Toxicol 2007;45(11):2219-27.

[32] www.oassisplan.com.

[33] Roseling H. Measuring effects in humans of dietary cyanide exposure from Cassava. Acta Horticulturae 1994;375:271-83.

[34] Rels.comxa.com

[35] Thompson LU, Cunnane SC. Flaxseed in Human Nutrition. $2^{\text {nd }}$ edn. USA: AOCS Publishing 2003:1-40. 